\title{
Analysis of the thermal loads required by a small-medium sized winery in the Mediterranean area
}

\author{
Alberto Barbaresi, ${ }^{1}$ Daniele Torreggiani, ${ }^{1}$ Francesco Tinti, ${ }^{2}$ Patrizia Tassinari ${ }^{1}$ \\ ${ }^{1}$ Department of Agricultural Sciences; and ${ }^{2}$ Department of Civil, Chemical, Environmental and Materials Engineering, \\ University of Bologna, Bologna, Italy
}

\begin{abstract}
Since the Nineties of the previous century winery design has been undergoing deep changes. Some factors are affecting the main design criteria, focusing on a new conception where the winery becomes more and more open to customers, energy demand reduction is a crucial goal driven by economic and environmental reasons, and the whole systems is aimed at the research of a renovate quality of the product.

The state of the art in this specific sector highlights how a reduction of the energy consumed by a winery can almost reduce to zero the carbon emissions of the whole wine-making process, as well as the existing lack of specific design criteria addressing the most recent above-mentioned trends and challenges, in particular for small and medium-sized farms, that on the whole account for a huge production in the Mediterranean area. The main aim of this work is to provide information about yearly thermal demand in the wine-making sector, by means of an integrated approach that considers the thermal loads required by room heating and air conditioning, must/juice pre-cooling, and fermentation cooling. Different models have been created and tested on a case study, in order to analyse the contribution of various farm design choices to the total energy demand. The most representative models are described and analysed in this work: they differ for harvesting modality, and materials and vertical distribution of the building
\end{abstract}

Correspondence: Alberto Barbaresi, Department of Agricultural Sciences, University of Bologna, viale Fanin 48, 40127 Bologna, Italy. E-mail: alberto.barbaresi@unibo.it

Key words: Winery design; integrated approach; thermal system sizing.

Acknowledgements: the authors would like to thank the farm winery Azienda Branchini, located in Toscanella di Dozza (Bologna, Italy), that hosted the research team and the experimental equipment and provided support in all phases of the research, and Fondazione Cassa di Risparmio di Imola for providing a financial contribution.

Received for publication: 12 January 2017.

Accepted for publication: 25 March 2017.

CCopyright A. Barbaresi et al., 2017

Licensee PAGEPress, Italy

Journal of Agricultural Engineering 2017; XLVIII(s1):670

doi:10.4081/jae.2017.670

This article is distributed under the terms of the Creative Commons Attribution Noncommercial License (by-nc 4.0) which permits any noncommercial use, distribution, and reproduction in any medium, provided the original author(s) and source are credited. envelope (aboveground $v s$ underground).

The results highlight the relevance of the three contributions in terms of total annual energy consumption, power peaks, and time distribution of energy demand over the year. The analysis of the data obtained by the different models have allowed to identify the strengths and potential critical issues, and to provide professionals, oenologists and farmers with useful elements to lend support in their decision making processes, as well as to define the next steps of the research, aimed at defining specific design criteria for small and medium-sized wineries.

\section{Introduction}

One of the most challenging phases in winery design concerns the integration of all the disciplines involved in the project, and the management of their mutual relationships. An integrated design should be able to assess the main consequences of the various choices, made in relation to a specific design sector, on all the other sectors. Winery design should involve several knowledge fields, such as engineering, architecture, oenology, meteorology, chemistry, physics, which are often addressed separately by different professional figures, thus increasing the risk of inaccurate building and system sizing and design.

The production of wine is a complex process made by several operations, such as grape cultivation, harvesting, delivery, and pressing, must fermentation, wine storage, and bottling. As every other transformation process, winemaking produces an environmental impact due to the use of chemical products (in the field and in the winery), to electric energy consumption for production and temperature control (during fermentation and storage), and thermal energy for cultivation and transportation. $\mathrm{CO}_{2}$ emissions, directly (fermentation) and indirectly (electric energy consumption, fuel combustion for cultivation and transportation, etc.) produced by the winemaking process, can be considered as an indicator of the environmental impact of the process, since $\mathrm{CO}_{2}$ is one the gas responsible for greenhouse effect and therefore for climate change. As it is well known, one of the most reliable methods for the evaluation of the carbon footprint is the life cycle assessment (LCA), that estimates the equivalent $\mathrm{CO}_{2}\left(\mathrm{CO}_{2 \mathrm{eq}}\right)$ emitted during the life cycle of a product, from cradle to grave, referred to a specific unit of the investigated product, called functional unit. This method can be very useful to identify the most polluting phases of an investigated process, and give important information for its improvement by means of the mitigation of the main negative effects. A review in the field of LCA analysis has allowed understanding the impact of thermal control energy consumption for the winemaking phase. Several LCA studies have been carried out to evaluate $\mathrm{CO}_{2}$ emissions in winemaking. Usually the LCA functional unit is $1 \mathrm{~L}$ or $750 \mathrm{~mL}$ (the content of a standard bottle, hereinafter bottle) of wine. Rugani et al. (2013) 
analysed 35 LCA studies about wine production, showing that the average $\mathrm{CO}_{2 \text { eq }}$ emitted in the whole process (from vineyard cultivation to end-of-life process) is $2.17 \mathrm{~kg} /$ bottle (standard deviation: $1.34 \mathrm{~kg} /$ bottle), of which $0.73 \mathrm{~kg} /$ bottle related to wine processing inside the winery. However, neither the $\mathrm{CO}_{2}$ absorbed by the vineyards, nor the $\mathrm{CO}_{2}$ emitted due to must fermentation (equal to about $100 \mathrm{~g} / \mathrm{bottle}$, as better explained in the following paragraphs) are considered in those studies. Ventura et al. (2007) calculated that the $\mathrm{CO}_{2}$ absorbed by the vineyards is about 22 tonnes per hectare. Considering an average grape yield of $12 \mathrm{t} / \mathrm{ha}$, and a wine conversion factor of $800 \mathrm{~L} / \mathrm{t}$ (Tassinari et al., 2009), the absorbed $\mathrm{CO}_{2}$ can be estimated in $1.62 \mathrm{~kg} /$ bottle. The literature lacks of researches specifically focused on the environmental impact of refrigeration in wineries. However, a LCA study by Notarnicola and Tassielli (2003) calculated the energy needed for refrigeration, for four different wine productions, obtaining values ranging between $33 \%$ and $50 \%$ of the whole winery energy consumption, excluding the energy for temperature control in the storage room. Even though the environmental impact of refrigeration is not directly considered, those studies indicate that a reduction in energy consumption caused by temperature control systems can drive to a substantial reduction in greenhouse gas emissions, bringing the wine industry very close to carbon neutrality.

The above-mentioned studies do not consider the energy demand of HVAC systems used for offices, laboratories and guest activities (and more and more frequently for wine storage rooms). Recently, a few authors have highlighted substantial changes in winery design, related to how people perceive aesthetic, environmental, and identity values in buildings and other spaces related to wine production, meant as the union of vineyards and wineries (Casamonti and Pavan, 2004). This has led to deep changes in building design. In particular, a growing importance has been given to consumer hospitality. Therefore, new spaces for wine tasting, cultural and leisure events are often included in the building (Tassinari et al., 2013). Obviously those spaces must be conditioned, entailing additional thermal loads to be provided. Such new perception pushed several wine farms to call famous architects - such as Renzo Piano, Santiago Calatrava, Herzog and De Meuron and others - to design their wineries, creating a sensible change also in the building architectural development.

Several works about winery design can be found in the scientific literature. In particular, Ayuga (1999) studied industrial wineries, Jacquet and Capdeville (2007) focused on innovation in systems and equipment, Failla et al. (2008) on work safety, and Fichera et al. (1995) on building and landscape sustainability. Nevertheless, despite the above-mentioned recent changes, the scientific literature shows a lack of studies about design criteria specifically focused on the construction of new small and medium-sized wineries, which prove capable of giving a fundamental contribution to the wine sector of the Mediterranean area, in particular in Italy, as shown in a study by Tassinari et al. (2009) focused on wineries whose annual production is less than $500,000 \mathrm{~L}$.

The present work aims to give a contribution to the definition of new criteria for the design of small and medium-sized wineries, by analysing the energy loads related to the thermal control of air conditioning, must/juice pre-cooling, and fermentation cooling, by means of an integrated approach, addressing the several variables (harvesting technique, building solutions, etc.) affecting the energy needs. More specifically, the study aims to assess the influence of the different variables on the energy load and peak.

\section{Materials and methods}

In order to calculate the thermal demand of a new winery, the study has been structured as follows.

The annual thermal energy load has been assessed with reference to a theoretical case of a new winery (hereinafter modelled winery) to be constructed for an annual production equal to the average of the more than 70 wineries in the same are (Bologna countryside) analysed in the above-mentioned study by Tassinari et al. (2009), equal to $360,000 \mathrm{~L} /$ year, thus assumed to be representative of small and medium-sized farm wineries in terms of production, building size, construction and envelope materials. A case study has allowed obtaining real data about wine production from an existing winery, to be used as a basis for this study (see next paragraph). The aspects that mainly influence the winery thermal needs related to must/juice pre-cooling, fermentation cooling, and building temperature control, have been identified as follows: grape harvesting modality, temperature control settings, building solutions. The main variables for each of those aspects have been defined. In particular, both manual and mechanic grape harvesting have been considered, as well as different combinations of envelope materials and vertical distributions of the building, and the winery functional units and rooms have been selected according to the scientific literature in order to analyse the building size and organization (see the following paragraphs and sub-paragraphs).

\section{Case study winery}

The case-study is a wine farm located in Bologna (northern Italy), with an overall land extension of 100 ha, of which 23 used to grow grape vines (Figure 1). The annual wine production amounts to $170,000-220,000 \mathrm{~L}$. The main building (30 m long, 20 $\mathrm{m}$ large, and $5 \mathrm{~m}$ high) of the farmstead houses both winemaking and wine storage. Previous studies (Barbaresi et al., 2014; Tinti et al., 2014; Barbaresi et al., 2015) allowed the research group to collect both general information about this farm and more specific data about its winemaking process. Based on that information, the production data of Table 1 , derived by doubling the actual extension of the vineyards, have been assumed as input data for the modelled winery. It is well known that some production factors (such as yield, sugar content, fermentation temperature) prove capable of affecting the winery energy needs. However, since they are closely related to wine quality and oenological procedures, the conditions of the case study have not be changed, nor considered as variables for this study.

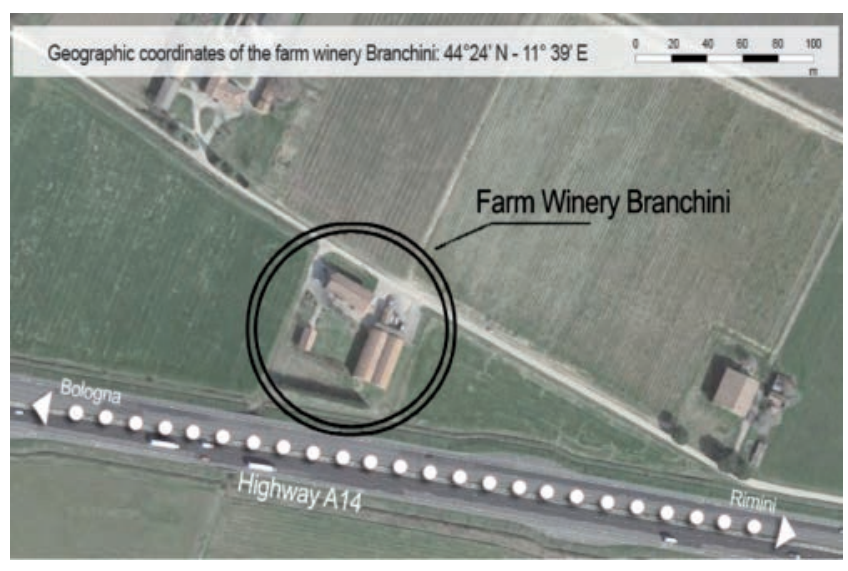

Figure 1. The location of case-study farm. 


\section{The modelled winery: functional units and rooms}

The model of the winery is based on farm data collected through a two-years survey and based on the results of previous studies. Main collected data are: vineyard area extension, grape yield, wine yield, harvesting periods, harvesting modalities, fermentation temperatures, number and size of wine-tanks and fermenters, farm building orientation. The modelled winery consists of the following functional units, defined according to Torreggiani et al. (2014): 1. Canopy for grape delivering protection; 2. Winemaking and storage area; 3 . Wine additive and wine-making tool storage; 4. Worker restrooms; 5. Worker locker-room; 6. Showers; 7. Bottling and packaging area; 8. Bottle storage; 9. Wine-ageing area; 10. Commercialization area; 11. Guest restrooms; 12. Tasting area; 13. Grape and wine analysis area; 14. Administration; 15. Sparkling area.

Except for the canopy (1), the functional units are hosted in specific building volumes, as follows:

Volume \#1 - (01.WIN) the volume hosting the wine-making area is the biggest room of the winery. Juice production, grape processing and must fermentation are hosted in the same volume, to ease the operative flows and guarantee flexibility during production and storage phases.

Volume \#2 - (02.CEL) the wine-aging room (9) - also called cellar - is close to the wine-making area and protected by excessive lighting, extreme temperatures, humidity and thermal swings. It is sized according to the amount of product and aging duration decided by the wine farm. A part of this room also hosts the tasting area (12).

Volume \#3 - (03.BOT) The bottling area (7), included in the modelled winery since in-house bottling is necessary for the considered amount of annual production, also hosts the bottle storage area (8).

Volume \#4 - (04.SPK) It hosts the autoclave for the sparkling process
(15). The incoming and outgoing product is moved by pumps.

Volume \#5 - (05.OFF) This volume hosts the offices for administration (14) and commercialization $(10,11)$ activities. It requires proper lighting and aeration, and air conditioning systems.

Volume \#6 - (06.LAB) This volume hosts equipment for grape and wine analyses (13) and workers restrooms (4). It is close to the winemaking area and conditioned.

Volume \#7 - (07.TEC) Wine additives and wine making equipment (3) are stored in this volume, together with the thermal systems. A part of this volume is dedicated to restrooms (4), locker-rooms (5) and showers (6).

Considering the equipment hosted in the winemaking area, the average height of the building is assumed to be 8 meters. A portion of the winery consists in a one-volume room hosting the wine making area (Volume \#1), while the other portion hosting the other volumes is divided horizontally in two stories. Therefore a part of the building, Volume \#8 - (08.VER), is dedicated to the vertical distribution (stairs and elevators, assumed to be unconditioned).

The 15 functional units have thus been divided into 8 volumes, organized on two stories. Their distribution has been designed taking into account functional, dimensional and thermal needs, as shown in Table 2.

\section{Energy demand}

As mentioned above, the total energy demand of the winery is the sum of: i) room heating and air conditioning: thermal loads for HVAC systems; ii) must/juice pre-cooling: energy required to lower the field temperature of grapes to the fermentation temperature; iii) fermentation cooling: heat removed during the fermentation phase.

These three contributions are totally different in terms of operation period, power, and total energy.

Table 1. The columns show: cultivar, kind of wine (red or white), vineyard extension, vineyard yield, harvested grape, wine yield, produced wine, fermentation temperature and grape Brix values. Input data for the modelled winery derived from information collected on the case study farm winery.

\begin{tabular}{|c|c|c|c|c|c|c|c|c|}
\hline Cultivar & Wine & $\begin{array}{c}\text { Vineyard } \\
\mathrm{Ha}\end{array}$ & $\begin{array}{l}\text { Yield } \\
\text { t/ha }\end{array}$ & $\begin{array}{c}\text { Grape } \\
t\end{array}$ & $\begin{array}{l}\text { Yield } \\
\text { L/t }\end{array}$ & $\begin{array}{c}\text { Wine } \\
\text { L }\end{array}$ & $\begin{array}{l}\text { Ferm } \mathrm{T} \\
{ }^{\circ} \mathrm{C}\end{array}$ & $\begin{array}{c}\text { Sugar } \\
{ }^{\circ} \mathbf{B}\end{array}$ \\
\hline Chardonnay & W & 12.5 & 10 & 125 & 790 & 98750 & 15 & 22 \\
\hline Albana & W & 12.5 & 10 & 125 & 780 & 97500 & 15 & 22 \\
\hline Sangiovese & $\mathrm{R}$ & 9.0 & 10 & 90 & 790 & 71100 & 25 & 24 \\
\hline Cabernet Sauvignon & $\mathrm{R}$ & 12.0 & 10 & 120 & 780 & 93600 & 25 & 24 \\
\hline Total & & 46.0 & & 460 & & 360950 & & \\
\hline
\end{tabular}

Ferm T, fermentation temperature.

Table 2. Distribution of the functional units of the winery in the various building volumes.

\begin{tabular}{|c|c|c|c|c|c|}
\hline Building volumes & $\begin{array}{l}\text { Hosted functional } \\
\text { units }\end{array}$ & $\begin{array}{l}\text { Height } \\
\text { (m) }\end{array}$ & Conditioning & $\begin{array}{l}\text { Ideal location } \\
\text { (required by law) }\end{array}$ & $\begin{array}{l}\text { Conditioning } \\
\text { (modelled winery) }\end{array}$ \\
\hline 01.WIN & (2) & 7 & Base floor & No & No \\
\hline 02.CEL & (9),(12) & I & Close to 01. & No & Yes \\
\hline 03.BOT & $(7),(8)$ & 3 & Ground floor & No & No \\
\hline 04.SPK & (15) & 3 & 1 & No & No \\
\hline $05 . \mathrm{OFF}$ & $(10),(11),(14)$ & 3 & Above ground & Yes & Yes \\
\hline 06.LAB & $(4),(13)$ & 3 & Close to 01. & Yes & Yes \\
\hline 07.TEC & $(3),(4),(5),(6)$ & 3 & Close to 01. & No & No \\
\hline 08.VER & - & 7 & 1 & No & No \\
\hline
\end{tabular}




\section{Room heating and air conditioning}

Wine is not considered as a perishable food, therefore food safety regulations do not provide specific prescriptions about storage temperature ranges. Nevertheless temperature and temperature swing can significantly affect wine quality (Marescalchi, 1965). Therefore, several wineries make use of conditioned rooms for wine storage and wine aging. Ideal temperature settings can be very different from one wine to another (Zamora, 2003; Martin and Canas, 2006; De Rosis et al., 2014; Barbaresi et al., 2017). The ideal storage temperature range assumed for the modelled winery is $12-18^{\circ} \mathrm{C}$. Besides buildings volumes strictly related to the winemaking process, the winery also hosts rooms with continuous human presence, such as offices and laboratories. For such areas the Italian Regulation (2006) requires that the room is heated in cold seasons. No prescription is given for other spaces, where wellbeing and safety of workers should be provided by means of suitable clothing. As explained in the previous Section, the volumes provided with conditioning systems are: 02.CEL, 05.OFF and 06.LAB. In the cellar (02.CEL) the wine is assumed to be kept constantly within the above-mentioned $12^{\circ} \mathrm{C}-18^{\circ} \mathrm{C}$ temperature range, and a $20 \%$ of red wine is assumed to be aged for 2 years in French barriques (corresponding to 300 barrels of 225-litres capacity). 05.OFF and 06.LAB are assumed to guarantee human comfort and operate according to seasons and working hours. The conditioning systems settings are summarized in Table 3.

\section{Must/juice pre-cooling}

Usually in the case-study farm wine grapes are harvested between mid-August and mid-October. In this period grape temperature can easily exceed $30^{\circ} \mathrm{C}$ (with peak values of $40^{\circ} \mathrm{C}$ ). These temperatures may activate fermentation before grapes are processed. For this reason the temperature of grapes (or more often of juice and must) is lowered to the fermentation temperature $\left(15^{\circ} \mathrm{C}\right.$ and $25^{\circ} \mathrm{C}$, for white and red wines respectively, according to Reynolds et al., 2001). In this work, the energy required for grape pre-cooling during the grape delivery period is calculated as follows [Eq. (1)]:

$$
Q_{x}=U_{x} \cdot y \cdot \rho \cdot h \cdot\left(T_{d}-T_{f}\right) \cdot a \mid \text { with }\left\{\begin{array}{l}
a=1 \text { if } T_{d}>T_{f} \\
a=0 \text { if } T_{d} \leq T_{f}
\end{array}\right.
$$

$Q_{x}[\mathrm{kWh}]$ is the heat to be removed on day $x ; U_{x}[\mathrm{Mg}]$ is the mass of grape delivered on day $\mathrm{x} ; \mathrm{y}[\mathrm{L} / \mathrm{Mg}]$ is the grape/juice/must that goes to the fermentation phase $(780 \mathrm{~L} / \mathrm{Mg}$ for white wine, 980 $\mathrm{L} / \mathrm{Mg}$ for red wine); $\rho[\mathrm{kg} / \mathrm{L}]$ is the density; $h[\mathrm{kWh} /(\mathrm{kg} \cdot \mathrm{K})]$ is the specific heat; $T_{d}$ is the grape temperature at the moment of delivery; $T_{f}$ is the fermentation temperature. In more detail, we have assumed that grapes are in thermal equilibrium with the outdoor environment during harvesting. Therefore, the outdoor temperature at harvesting time, hereinafter $T_{d}$, has been assigned to grapes. The pre-cooling process should be completed before the delivery of the following day, therefore is assumed to last $24 \mathrm{~h}$. A weather station, installed $100 \mathrm{~m}$ far from the winery, allowed us to record hourly weather data since 2012. According to Boulton et al. (1998), the specific heat of the grape/juice/must is $3.8 \mathrm{~kJ} /(\mathrm{kg} \cdot \mathrm{K})$ $(0.011 \mathrm{kWh} /(\mathrm{kg} \cdot \mathrm{K}))$, and its density is $1090 \mathrm{~kg} / \mathrm{m}^{3}$.

\section{Fermentation cooling}

As it is well know, alcoholic fermentation is an exothermic reaction that takes place inside wine tanks. The assumptions in this work are as follows: i) the tanks are considered perfectly insulated; ii) the temperature of the must in the tank inlet is equal to the temperature set for the fermentation (thanks to must/juice pre-cooling).

Therefore, the heat to be removed is equal to the heat produced by ethanol fermentation, and is calculated by means of Eq. (2):

$\mathrm{C}_{6} \mathrm{H}_{12} \mathrm{O}_{6}=2 \mathrm{CH}_{3} \mathrm{CH}_{2} \mathrm{OH}+2 \mathrm{CO}_{2}+25 \mathrm{kcal} / \mathrm{mol}$

in standard conditions.

Eq. (2) shows that the total energy released by the fermentation process depends uniquely on the sugar amount in the must (assumed to be 22-24 Brix degrees). The heat release rate changes over time (Boulton, 1980) and is calculated according to Eq. (3):

$P_{x}=\frac{E}{\sigma \sqrt{2 \pi}} \cdot e^{-\frac{(x-\mu)^{2}}{2 \sigma^{2}}}$

where $P_{x}$ is the energy released in the specific hour expressed in $\mathrm{kWh} / \mathrm{h}, E$ is the total energy that will be released in the whole fermentation process by that daily delivery expressed in $\mathrm{kWh}$, the mean corresponds to the half of the total fermentation time, and the standard deviation $\sigma$ is calculated as one sixth of the total fermentation time. Total fermentation time, $t$, is evaluated in 20 days for $15^{\circ} \mathrm{C}$ fermentation temperature (white wines), and 10 days for $25^{\circ} \mathrm{C}$ fermentation temperature (red wines), according to Boulton (1980), Coleman et al. (2007) and Ough (1966). Therefore:

$$
\mu=24 \cdot t_{f} / 2 \text { and } \sigma=24 \cdot t_{f} / 6
$$

Moreover, Eq. (3) shows that fermentation temperature, conditioning fermentation duration, affects heat release rate. Figure 2 shows the results of Eq. (3) applied to 1 ton of wine fermented at $15^{\circ} \mathrm{C}$ (white wine in our work), and to 1 ton of wine fermented at $25^{\circ} \mathrm{C}$ (red wine in our work). The total energy released is about 280 $\mathrm{kWh}$ for both fermentations, but energy rates (power) and release durations are sensibly different. Wine fermented at $15^{\circ} \mathrm{C}$ releases heat in about $500 \mathrm{~h}$, with a maximum power of $1.4 \mathrm{~kW}$, while wine fermented at $25^{\circ} \mathrm{C}$ in about $250 \mathrm{~h}$, with a maximum power of 208

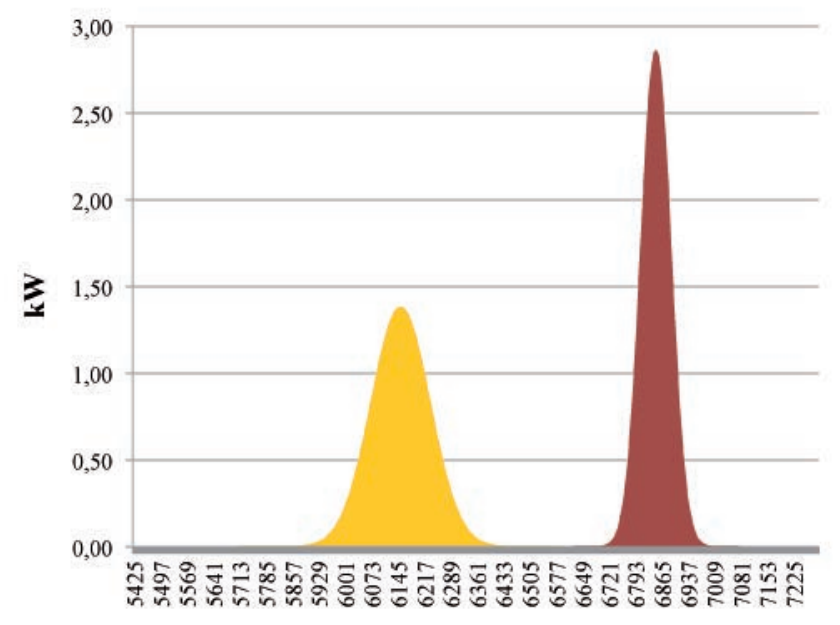

Figure 2. Heat released by 10 tons of wine during fermentation, the yellow area represents wine fermented at $15^{\circ} \mathrm{C}$, the red curve wine fermented at $25^{\circ} \mathrm{C}$. 
$\mathrm{kW}$. Finally, the graph in Figure 2 confirms the dependence of power on fermentation duration, this meaning that variations in fermentation temperature would lead to variations in thermal system sizing. However, considering variables affecting wine quality or farm strategies lies outside the scopes of this research.

\section{Variables}

Most of the operations made in the winery affect its overall energy demand. Moreover, since thermal energy is used also for room climate control, the building itself affects the total energy load. Harvesting modality and vertical distribution and thermal characteristics of the building envelope have been considered as follows.

\section{Harvesting modality}

During harvesting grapes are not delivered constantly, but according to time trends related to cultivar, harvesting modality, weather conditions, etc. It is well known that delivery time scheduling is very different in mechanical and manual harvesting, the total amount of grape being equal. In particular, manual harvesting usually delivers grapes more times per day and over a longer period than mechanic one. Such differences affect: i) the energy required for must/juice pre-cooling: depending on the difference between field temperature - variable through time - and fermentation temperature, different heat amounts have to be removed from grape/juice/must; ii) the energy rate (power) for grape and fermentation cooling: whilst the total energy does not depend on delivery time scheduling, energy rate (power of the system) strongly depends on it. While mechanical harvesting is a nonselective and faster procedure, it is well known that manual har- vesting allows specialized operators to select only those grapes that meet specific conditions, and is generally used for high-quality wines or when mechanical harvesting is not possible due to particular conditions (e.g., steep slopes). Independently from any evaluation from an oenological point of view, both harvesting modalities have been considered in this work for the analysis of thermal loads: i) mechanical harvesting (code: mec): delivery time scheduling is calculated based on the daily logs of the last 5 years of the case study farm, by adapting them to the extension of the vineyards assumed for the modelled winery (Figure 3A and B); ii) manual harvesting (code: man): the mass of grape delivered on day $\mathrm{x}$ for a specific cultivar is calculated referring to a Gaussian distribution according to Eq. (5):

$$
U_{x}=\frac{U_{t}}{\sigma \sqrt{2 \pi}} \cdot e^{-\frac{(x-\mu)^{2}}{2 \sigma^{2}}}
$$

where $U_{t}$ is the amount of grapes to harvest in a season, $\mu$ is half of the harvesting duration of the specific cultivar (number of days), and the standard deviation $\sigma$ is calculated as a sixth of the harvesting duration of the specific cultivar. This distribution simulates a harvesting pattern characterized by long duration and low delivery peaks (Figure 3C and D).

\section{Vertical distribution of the building}

According to a winery survey carried out by (Torreggiani et al., 2014) both totally above-ground and partially underground buildings are common in the area under study. These latter ones are mainly used in hilly

\section{Grape delivery}

Mechanic harvesting

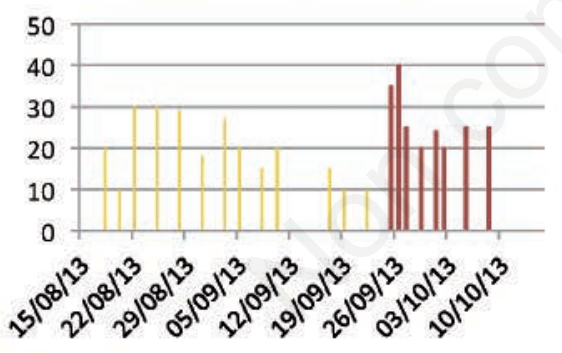

A) Date $v s$ grape delivered $[\mathrm{Mg}]$

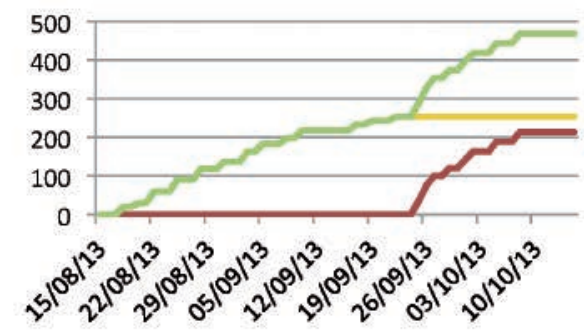

C) Cumulative curve - date $v$ s total delivery $[\mathrm{Mg}]$

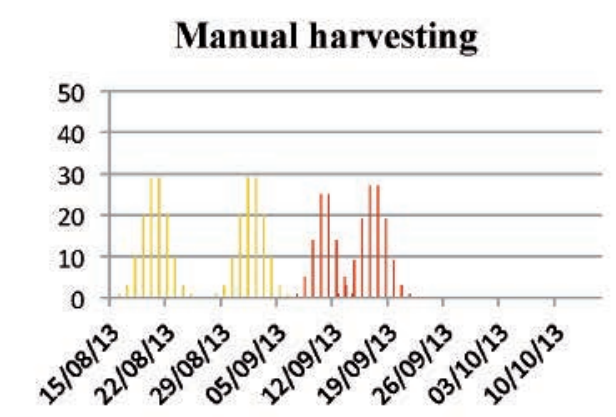

B) Date $v s$ grape delivered $[\mathrm{Mg}]$

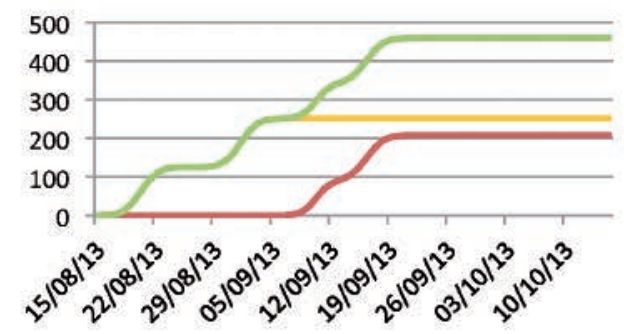

D) Cumulative curve - date $v$ s total delivery $[\mathrm{Mg}]$

Figure 3. Distributions and cumulative curves of grape delivery under manual and mechanical harvesting. Yellow line represent grape for white wine, red for red wine and green the total. 
areas, where natural slopes are used to create underground rooms suitable for gravity fed winemaking and for wine aging in summer periods.

The modelled winery takes into account the two following layouts: i) totally above ground (code: $A G R$ - Figure 4A: all the volumes are aboveground; ii) partially underground (code: $P U G$ (Figure 4B): the basement floor is about $4 \mathrm{~m}$ below the ground level, therefore the winemaking room is partially underground, and all the other rooms are located either underground or at the ground level. AGR and PUG layouts lead to different room locations, and thus different area and volume for the same room, due to design constraints. Layouts, sections and information (area, volume and location) of each room of the building in both configurations are described in Figure 5. Moreover for architectural style reason the roofs are different: hip roof (four-pitched-roof) for AGR and skillion roof (mono-pitched-roof) for PUG.

\section{Building envelope thermal characteristics}

For those building volumes that have to be heated due to continuous human presence, Italian building regulation provide specific thresholds for the overall transmittance of internal and external walls and the roof, in order to reduce energy consumption for room conditioning in new constructions. Italy is divided into six climatic zones (from zone A to zone F), for which different thermal values are provided (Table 4 ). The modelled winery is assumed to be located in Zone E (as the case study winery).

This work considers two scenarios, as follows: i) thermal characteristics provided by law are set only for those building volumes that have to comply with mandatory energy saving prescriptions (code: $\min$ ) (Table 5); ii) thermal characteristics provided by law are set for all building volumes of the winery (code: law) (Table 6).

Table 3. Room temperature settings assumed for heating and air conditioning control in the modelled winery.

\begin{tabular}{lcccc} 
& & & \multicolumn{2}{c}{ Warm seasons } \\
Volume & Working hours & Out of WH & Working hours & Out of WH \\
02.CEL & $12^{\circ} \mathrm{C}<\mathrm{T}<18^{\circ} \mathrm{C}$ & $12^{\circ} \mathrm{C}<\mathrm{T}<18^{\circ} \mathrm{C}$ & $12^{\circ} \mathrm{C}<\mathrm{T}<18^{\circ} \mathrm{C}$ & $12^{\circ} \mathrm{C}<\mathrm{T}<18^{\circ} \mathrm{C}$ \\
$05 . \mathrm{OFF}$ & $\mathrm{T}>20^{\circ} \mathrm{C}$ & $\mathrm{T}>16^{\circ} \mathrm{C}$ & $\mathrm{T}<26^{\circ} \mathrm{C}$ & $\mathrm{T}<30^{\circ} \mathrm{C}$ \\
\hline $06 . \mathrm{LAB}$ & $\mathrm{T}>20^{\circ} \mathrm{C}$ & $\mathrm{T}>16^{\circ} \mathrm{C}$ & $\mathrm{T}<26^{\circ} \mathrm{C}$ & $\mathrm{T}<30^{\circ} \mathrm{C}$ \\
\hline
\end{tabular}

Table 4. Transmittance limit values according to Italian regulation.

\begin{tabular}{lcccccc} 
Limit values $\left[\mathrm{W} /\left(\mathrm{m}^{2} \mathrm{~K}\right)\right]$ & $\mathbf{A}$ & $\mathbf{B}$ & $\mathbf{D}$ & $\mathbf{E}$ & $\mathbf{F}$ \\
Vertical opaque structures & 0.62 & 0.48 & 0.40 & 0.36 & 0.33 & 0.33 \\
Roofs & 0.38 & 0.38 & 0.38 & 0.32 & 0.30 & 0.29 \\
\hline Floors & 0.65 & 0.49 & 0.42 & 0.36 & 0.33 & 0.32 \\
Conditioned room divisions & 0.80 & 0.80 & 0.80 & 0.80 & 0.80 & 0.80 \\
\hline
\end{tabular}

The values in italics refer to Emilia Romagna Region.

Table 5. Values of density and transmittance of envelope surfaces for the min scenario.

\begin{tabular}{llccc} 
Construction & Position & AC room & Density $\left[\mathrm{kg}^{2} \mathrm{~m}^{3}\right]$ & Transmittance [W/( $\left.\left.{ }^{2} \mathbf{K}\right)\right]$ \\
Wall & Outdoor & No & 230 & 2.42 \\
& & Yes & 244 & 0.33 \\
& Indoor & No & 207 & 1.39 \\
\multirow{2}{*}{ Roof } & & Yes & 80 & 0.80 \\
& Outdoor & No & 300 & 1.61 \\
Floor & & Yes & 304 & 0.29 \\
& Outdoor & No & 720 & 2.94 \\
\hline
\end{tabular}

Table 6. Values of density and transmittance of envelope surfaces for the law scenario.

\begin{tabular}{llccc} 
Construction & Position & AC room & Density $\left[\mathrm{kg}^{2} / \mathrm{m}^{3}\right]$ & Transmittance [W/( $\left.\left.{ }^{2} \mathrm{~K}\right)\right]$ \\
Wall & Outdoor & Both & 244 & 0.33 \\
& Indoor & Both & 80 & 0.80 \\
Roof & Outdoor & Both & 304 & 0.29 \\
\hline Floor & Outdoor & Both & 438 & 0.33 \\
\hline
\end{tabular}




\section{AGR}

PUG
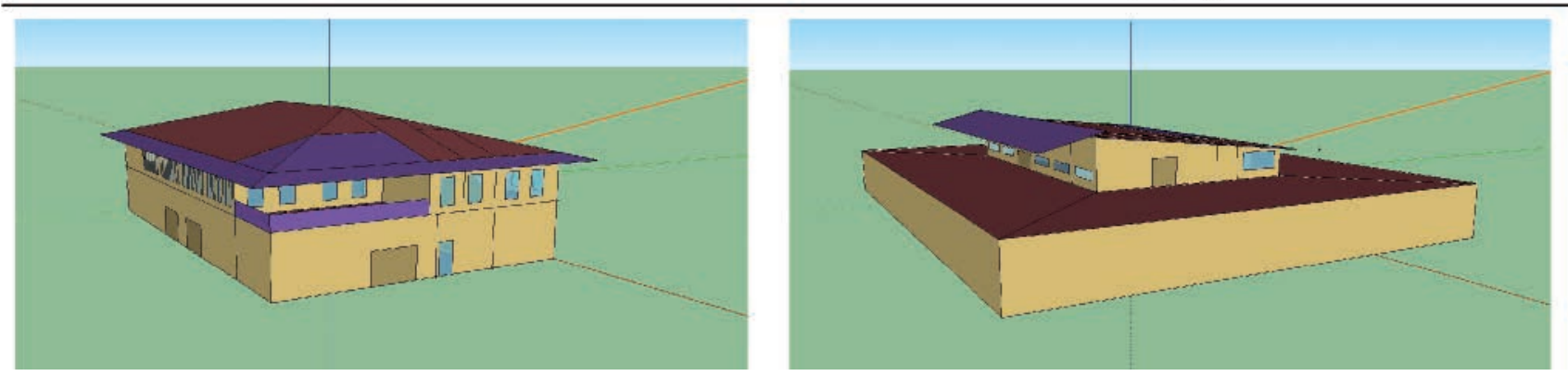

Figure 4. EnergyPlus models.

AGR
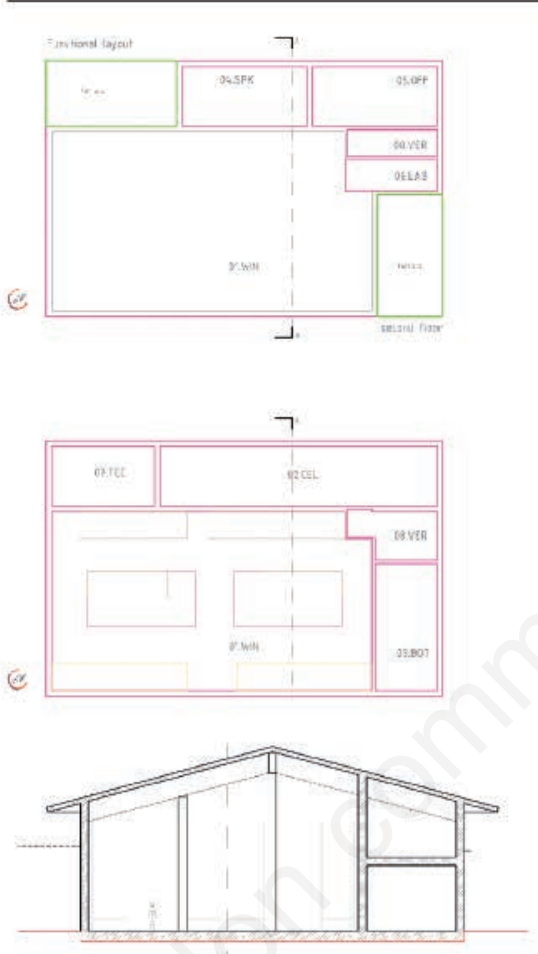

A) Layouts: first and second level, section

\begin{tabular}{llll}
\hline Room & Area $\left[\mathrm{m}^{2}\right]$ & Volume $\left[\mathrm{m}^{3}\right]$ & Level \\
01.WIN & 526.19 & 5032.01 & $1 / 2$ \\
02.CEL & 159.00 & 715.50 & 1 \\
03.BOT & 75.00 & 337.50 & 1 \\
04.SPK & 72.00 & 318.87 & 2 \\
05.OFF & 75.00 & 322.81 & 2 \\
06.LAB & 26.25 & 125.62 & 2 \\
07.TEC & 60.00 & 270.00 & 1 \\
08.VER & 37.56 & 283.29 & $1 / 2$ \\
\hline Total & 1031.00 & 7405.60 &
\end{tabular}

C) Room dimensions and vertical location

\section{PUG}
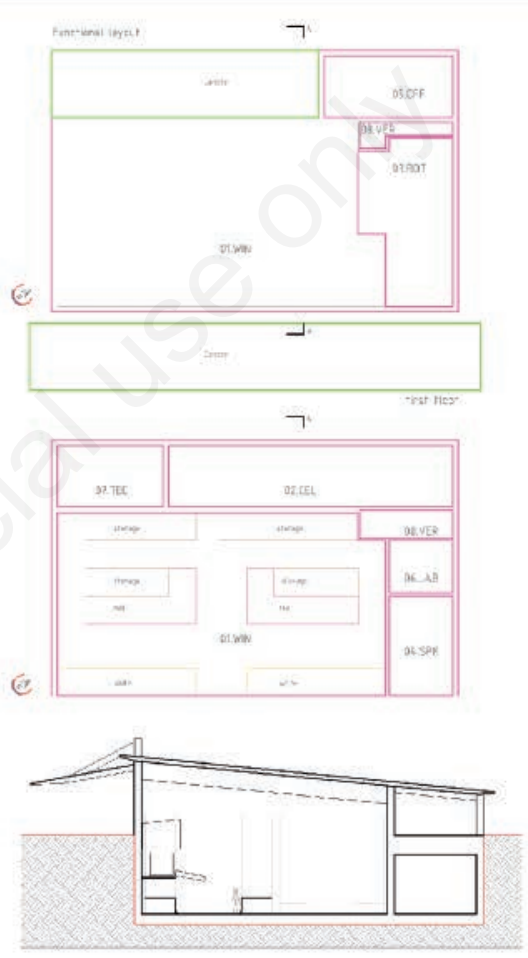

B) Layouts: underground and first level, section

\begin{tabular}{llll} 
Room & Area $\left[\mathrm{m}^{2}\right]$ & Volume $\left[\mathrm{m}^{3}\right]$ & Level \\
01.WIN & 522.97 & 5496.58 & $\mathrm{UG} / 1$ \\
02.CEL & 156.00 & 936.00 & $\mathrm{UG}$ \\
03.BOT & 110.64 & 533.14 & 1 \\
04.SPK & 60.76 & 364.56 & $\mathrm{UG}$ \\
05.OFF & 72.00 & 258.74 & 1 \\
06.LAB & 30.38 & 182.28 & $\mathrm{UG}$ \\
07.TEC & 63.00 & 378.00 & $\mathrm{UG}$ \\
08.VER & 24.64 & 247.00 & $\mathrm{UG} / 1$ \\
\hline Total & 1040.39 & 8396.30 &
\end{tabular}

D) Room dimensions and vertical location

Figure 5. Layouts and information of the modelled winery. AGR (on the left), PUG (on the right). 


\section{Energy modelling}

The energy demand for air conditioning is calculated by means of the EnergyPlus 8.1 software (U.S. Department of Energy, 2013). The thermal zoning has been created using OpenStudio 1.4. A single thermal zone has been created for each conditioned volume as identified in the previous paragraphs (02.CELL, 05.OFF, 06.LAB), since their indoor temperature must be kept uniform according to thermostat settings explained in the previous paragraphs. A single thermal zone has been created for each one of the other volumes as well, except for 01 .WIN, that called for the definition of 2 thermal zones identified by means of an horizontal subdivision, located at a height of 4 meters above the floor level, in order to take into consideration the temperature gradient (Barbaresi et al., 2015; PorrasAmores et al., 2014). In total 8 thermal zones have been created. The main input data are as follows: i) temperature settings have been set as described in the previous paragraphs; ii) construction thermal values have been set as described in the previous paragraphs; iii) in the PUG layout, the ground has been modelled as a fictitious space surrounding the winery, according to Mazarrón and Cañas Guerrero (2008); iv) the barriques have been modelled as objects having the same surface, volume and thermal characteristics of the wine, according to Boulton et al. (1998); v) building orientation (the azimuth of the main axis of the building is $32^{\circ}$ ) has been set respecting the constraints related to roads (including the highway running close to the building under study), and orientation of existing buildings (aligned to the historical roman centuriation).

\section{Weather file}

As it is well-known, weather conditions strongly affect thermal simulations. EnergyPlus website provides over 2100 weather files for locations all over the world. The closest weather file location is $32 \mathrm{~km}$ far from the case study (at the Bologna airport), and is located in a complete different environment, within a urbanized context. For this reason, we have created a specific weather file for this location, to be used for the simulations. The weather file has been created using data surveyed in 2013 through a weather station located $100 \mathrm{~m}$ far from the modelled winery. Precisely, main collected data are: temperature, humidity, pressure, rainfall, wind speed. Other important data, such as horizontal solar radiation, were taken using the weather station net Dext3r provided by ARPAE (Agenzia regionale per la prevenzione, l'ambiente e l'energia dell'Emilia-Romagna - Agency for protection, environment and energy of the Emilia-Romagna region, 2017). Added data were taken less than $10 \mathrm{~km}$ far from the winery in a very similar environment (open countryside). Figures 6 and 7 show respectively daily average temperatures and daily solar radiation stored in the weather file used for the simulations.

\section{Ground temperatures}

Considering the energy exchange between the building and the surrounding ground is a crucial issue, due to the related heat transfer calculations. In fact, EnergyPlus is based on one-dimensional heat transfer, while the ground heat transfer is two-three dimensional. Moreover, the time scale of input data is remarkably different: outdoor air data are provided hourly, ground temperatures are provided monthly. Despite these problems, EnergyPlus calculates the heat transfer between underground walls and slabs and the surrounding ground, warning the user about the possible unreliability of the results (U.S. Department of Energy, 2013). For this reason, EnergyPlus provided pre-process programs able to improve results reliability just for conditioned rooms. Nevertheless, Barbaresi et al. (2014) demonstrated that proper modeling can lead to reliable solutions. Specifically, in this work the ground has been modelled as a thermal zone surrounding the underground walls and slab, according to Mazarrón et al. (2012). The ground temperatures applied to the ground thermal zone have been taken from an on-site underground temperature survey (Tinti et al., 2014, 2015).

\section{Models, assessment and indicators}

Eight models have been created, corresponding to all possible combinations of the three variables related to vertical distribution, envelope materials, and harvesting modality (AGR/PUG, min/law, $\mathrm{man} / \mathrm{mec}$ ). For each model, the three contributions related to thermal energy (air conditioning, must/juice pre-cooling, and fermentation cooling) have been calculated and summed, to analyse the weight of each contribution in terms of total energy and power peak, to show the energy need throughout 2013, and to find the period of the year in which both positive and negative thermal loads are required at the same time (heating and cooling overlaps). Given the slight differences in room size between the AGR and

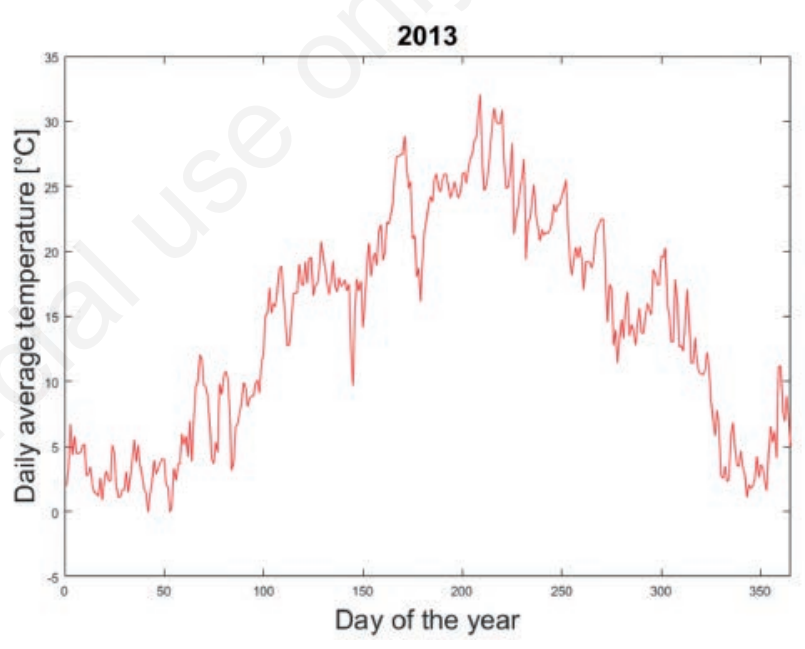

Figure 6. Daily average temperatures recorded by the on-site weather station.

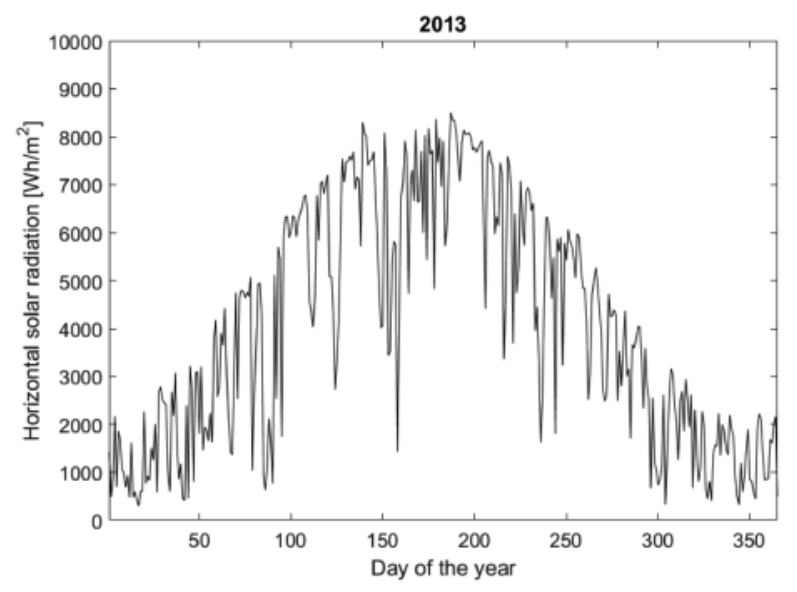

Figure 7. Daily horizontal solar radiation recorded by regional weather station net. 
PUG models, a specific energy indicator, calculated as the ratio of the energy demand to the room volume $\left(\mathrm{kWh} / \mathrm{m}^{3}\right)$, has been used to compare the thermal load for heat and air conditioning.

\section{Results and discussion}

For the sake of brevity, the results of only two of the eight models are presented globally in this Section: AGR.min.mec and PUG.law.man, hereinafter called Model 1 and Model 2. They show the highest and lowest values in terms of total energy consumption and specific energy needs, respectively, and cover all possible values of the parameters under study.

\section{Room heating and air conditioning}

Figure 8A-D shows the thermal loads calculated for AGR.min.mec and PUG.law.man. In particular, Figure 8A and B shows the total energy required to keep the temperature within the defined intervals for the cellar (02.CELL), the offices (05.OFF) and the laboratory (06.LAB), both for heating, in red, and air conditioning (AC), in blue. In both models, the cellar (located on the lowest floor) shows the highest energy need, however with a great difference between the two models: $19257 \mathrm{kWh}$ in AGR.min.mec, and $9844 \mathrm{kWh}$ in PUG.law.man. On the contrary, the offices, in both models located aboveground, immediately under the roof, show similar energy needs (5967 kWh in AGR.min.mec, 6699 $\mathrm{kWh}$ in PUG.law.man), as well as the laboratories, located on the second floor in AGR.min.mec and underground in PUG.law.man (2675 kWh in AGR.min.mec, $2493 \mathrm{kWh}$ in PUG.law.man).

Table 7 shows that the highest specific energy is required by the cellar of Model $1\left(26.91 \mathrm{kWh} / \mathrm{m}^{3}\right)$, almost equal to three times that of Model 2, where the ground has a significant beneficial effect on temperature control. On the contrary, the specific energy demand for the offices is higher in Model $2\left(26.89 \mathrm{kWh} / \mathrm{m}^{3}\right)$. In fact in this model the north-east side of the room is not protected by the roof overhang (differently to the Model 2 offices) increasing the exposure to the sun in particular in warmer seasons. This result indicates that the attention to the architectural details can provide a better effect than a good insulation. The laboratories are located in the lowest floor in both models with a small exposure to the external environment, but the specific energy in Model 2 is equal to $13.84 \mathrm{kWh} / \mathrm{m}^{3}$ ( vs $21.29 \mathrm{kWh} / \mathrm{m}^{3}$ of Model 1), this confirming the positive effect of the ground on indoor temperature control. Considering all conditioned volumes, Model 2 requires half the specific energy of Model $1\left(12.84 \mathrm{kWh} / \mathrm{m}^{3}\right.$ vs $23.87 \mathrm{kWh} / \mathrm{m}^{3}$, respectively). These results confirm the importance of insulation and underground thermal properties, but also underlines the importance of the building layout.

In order to have a complete comparison of the models, the same table reports also the results obtained by the other architectural combinations: PUG.min and AGR.law. It is interesting to notice the insertion of insulation in all the rooms strongly affects the total specific energy, with a $43 \%$ reduction of energy required per cubic meter. In more detail, the difference is related to the cellar room, since the other two conditioned rooms show similar consumptions. The comparisons between PUGs models highlights that the specific energy need of 02.CELL and 06.LAB is reduced. That result is not originated by the room walls, since they are made by the same construction in both model: it comes from the improved insulation of the adjacent rooms (such as 01.WIN, 04.SPK, 07.VER). This result confirms the importance of the insulation of internal partitions and insulation of unconditioned rooms. Globally, Table 7 shows that insulation improves both PUG (17\%) and AGR models (43\%). Moreover, insulation of AGR makes AGR and PUG performance similar, this meaning that insulation required by law can be compared to efficiency of underground solutions.

\section{Must/juice pre-cooling}

The results show that mechanical harvesting requires less energy than manual one (2840 vs $3088 \mathrm{kWh}$; Table 8$)$. The peaks in average hourly power are similar in both models (respectively equal to 19.68 and $17.05 \mathrm{kWh} / \mathrm{h}$, contrarily to the total energy where Model 1 exhibits a higher value (see light blue columns in Figure $8 \mathrm{E}$ and $\mathrm{F}$ ). The total energy required for must/juice precooling is $10 \%$ of the energy for room temperature control in Model 1 and $17 \%$ in Model 2. Differently the power peak is the $50 \%$ higher than the power required to heat and cool the whole building in Model 1 and 64\% higher in Model 2. Since uncertainty in predicted outdoor temperature trends can significantly affect the reliability of the estimated must/juice pre-cooling thermal load, as a cautionary approach, irrespective of the chosen harvesting modality, a proper sizing of the thermal system may consider both harvesting modalities and take into account the highest values of total energy and power peak.

\section{Fermentation cooling}

Energy required for fermentation cooling is the same for the two Models $(12,935 \mathrm{kWh}$ vs $12,933 \mathrm{kWh})$. On the contrary, the peak in average hourly power is different (44.66 vs $29.99 \mathrm{kWh} / \mathrm{h}$ ), in relation to the different delivery time schedules (see blue columns in Figure 8E and F). The energy required for fermentation cooling is similar to the energy required to cool the whole building in Model 1, and more than double in Model 2. The fermentation power peak is 4 times higher than the power required to control the temperature in the building in Model 1 and 3 times higher in Model 2 , therefore power sizing should be calculated based on fermentation cooling peak power. Similarly to must/juice pre-cooling, uncertainties in predicting outdoor climatic conditions can have effect on the estimation of energy and power peak for fermentation cooling. Similarly to the must/juice pre-cooling, the energy and power peak related to fermentations are hard to predict since they are strongly affected by the weather conditions, and the underestimation of the fermentation cooling can drive to undersize of the whole system.

Table 7. Specific energy required by the rooms of the winery. Values are expressed in $\left[\mathrm{kWh} / \mathrm{m}^{3}\right]$.

\begin{tabular}{lcccc} 
& AGR.min & PUG.law & PUG.min & AGR.law \\
02.CEL & 26.91 & 9.07 & 11.41 & 10.13 \\
05.OFF & 18.48 & 26.89 & 26.28 & 18.32 \\
\hline 06.LAB & 21.29 & 13.67 & 21.46 & 21.57 \\
Total & 23.97 & 12.84 & 15.53 & 13.65 \\
\hline
\end{tabular}




\section{General discussion}

In general, Model 1 (AGR.min.mec) requires more energy (43,000 vs 33,000 kWh) than Model 2 (PUG.law.man), and the difference is mainly related to the contribution for room heating and air conditioning $(27,000$ vs $17,000 \mathrm{kWh})$. The contribution for room heating and air conditioning, must/juice pre-cooling and fermentation cooling represent the $64 \%, 6 \%, 30 \%$ in Model 1 and $52 \%, 9 \%$ and $39 \%$ in Model 2, respectively. Energy for heating is the $38 \%$ of the total energy in Model 1, and $36 \%$ in Model 2. In both models the highest energy demand comes from the building thermal control, that, at the same time, shows the lowest power peak. The lowest energy demand is related to must/juice pre-cooling, and the highest power peak is related to fermentation cooling.

Figure $8 \mathrm{G}$ and $\mathrm{H}$ shows how the three above-mentioned contributions require thermal loads almost independently of each other: the total power peak is caused by fermentation cooling in Model $1(44.66 \mathrm{kWh} / \mathrm{h})$, and is a little higher than fermentation cooling peak in Model 2 (33.66 vs $29.99 \mathrm{kWh} / \mathrm{h}$ ). Therefore a system sized based on fermentation cooling power peaks can provide thermal energy for the whole building and take advantage of any overlap between positive (heating) and negative loads (cooling). In the modelled winery, heating and cooling demands overlap for 92 h $(24 \mathrm{kWh})$ in Model 1 and $169 \mathrm{~h}(35 \mathrm{kWh})$ in Model 2.

\section{Conclusions}

This work aimed to provide information for thermal system sizing in a small/medium-sized winery in the Mediterranean area. The main goal was to analyse the different contributions to energy consumption, thus deriving useful information to reduce the energy need and the environmental impact, without affecting the standards of the wine making process set based on enological evaluations. The total energy demand is the sum of room heating and air conditioning, must/juice pre-cooling, and fermentation cooling. Two models have been compared, covering different harvesting modality, building envelope material and vertical distribution (underground, aboveground), and providing data about all thermal contributions over one year. The results have highlighted the relevance of the three thermal contributions in total energy, power peak and period, and quantified how some variables, not directly connected to fermentation, can affect the power peak in fermentation cooling. The integrated approach used in this work allows to: - identify potential critical issues. The results show the highest

contribution in terms of energy need and power peak, and the relevance of each contribution on the total system;

- identify strengths. The results allow to identify periods where positive and negative thermal loads overlap, thus providing useful information for the design of the system. In order to provide energy for fermentation cooling, the thermal system produces free heating that can be used for other purposes, such as room or water heating;

- provide the enologist with useful elements to lend support to decisions in the wine-making process. For example, the abovementioned free heating can also be used for grape drying in the production of sweet dessert wines (passito). Evidence-based choices can be made about the adoption of must/juice pre-cooling (not widespread used at the moment), in order to better plan the fermentation phase: the results show that the impact of must/juice pre-cooling is compatible with fermentation cooling in terms of power peak, and its contribution on total energy consumption is moderate (less than $10 \%$ in the modelled winery);

- lend support to farm management. The results have highlighted how several winemaking procedures and winery design aspects have consequences on energy demand and power peaks. The proposed approach, providing information on energy consumptions, can be considered as a tool allowing farmers to take decisions also based on the optimization of operating costs;

- provide inputs for further research works in the field. The results can help researchers in defining the most relevant goals for further research aimed to reduce the environmental impact of winemaking. In particular, the results suggest focusing on room air conditioning for the reduction of the total energy demand, and on fermentation cooling for the reduction of power peaks. Specific researches on the use of shallow geothermal systems to provide thermal energy all year round and lower fermentation peaks, and on cold energy storages to lower energy peaks in the harvest/fermentation period are currently being carried out by the authors, and will be the subject of future publications.

Finally, the work confirms the importance of insulation compared to underground solutions. Wine production has been taking advantage of the well-known thermal properties of the ground for centuries. Nowadays insulation materials can play a crucial role. The work shows that the addition of insulation material to walls and roof, according to the energy saving law, allows the building to achieve energy performance similar to underground solutions. Moreover, insulation of horizontal and vertical partitions applied also to unconditioned rooms gives an additional positive contribution to conditioned rooms. Such analysis, carried out before construction or in retrofit intervention, combined with a cost analysis, can quantify benefits coming from the two solutions. A further cost analysis can complete the information, helping professionals

Table 8. Energy demand and average hourly power peaks.

\begin{tabular}{|c|c|c|c|c|c|c|c|c|}
\hline \multirow{2}{*}{ Energy demands } & \multicolumn{4}{|c|}{ AGR.min.mec } & \multirow[b]{2}{*}{ Heating kWh } & \multirow[b]{2}{*}{ Cooling kWh } & \multicolumn{2}{|c|}{ PUG.law.man } \\
\hline & HeatingkWh & Cooling kWh & Total kWh & Peak kWh/h & & & Total kWh & Peak kWh/h \\
\hline Heating \& AC & 16728 & 11171 & 27899 & 13.28 & 12195 & 5484 & 17679 & 10.38 \\
\hline 02.CEL & 9550 & 9707 & 19257 & 5.13 & 5071 & 3414 & 8485 & 3.03 \\
\hline 05.OFF & 4815 & 1152 & 5967 & 5.71 & 4630 & 2069 & 6699 & 5.21 \\
\hline 06.LAB & 2363 & 312 & 2675 & 2.97 & 2493 & 0 & 2493 & 3.01 \\
\hline Must cool. & 0 & 2840 & 2840 & 19.68 & 0 & 3088 & 3088 & 17.05 \\
\hline Fermentation cooling & 0 & 12935 & 12935 & 44.66 & 0 & 12933 & 12933 & 29.99 \\
\hline Total & 16728 & 26947 & 43675 & 44.66 & 12195 & 21504 & 33699 & 33.59 \\
\hline
\end{tabular}

The values in italics refer to the whole building. 
AGR.min.mec

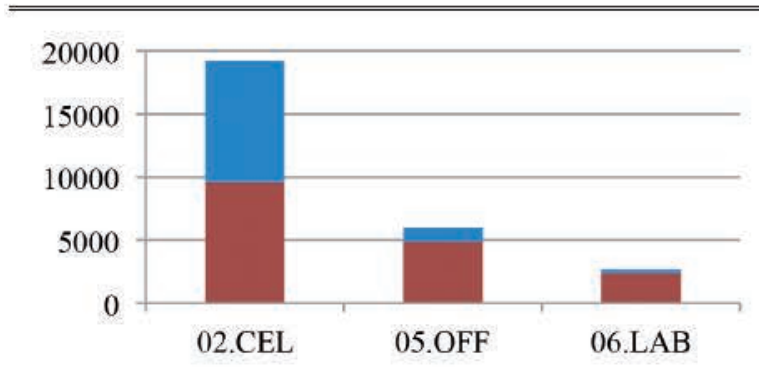

A) Heating and AC ( $\mathrm{x}$ - rooms; $\mathrm{y}$ - energy [ $\mathrm{kWh}]$ )

\section{PUG.law.man}

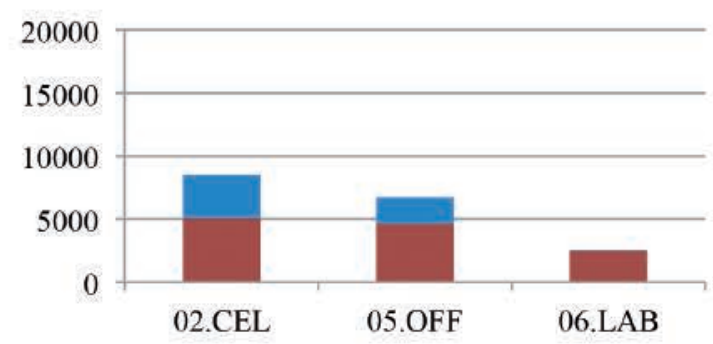

B) Heating and AC (x - rooms; y - energy [kWh])

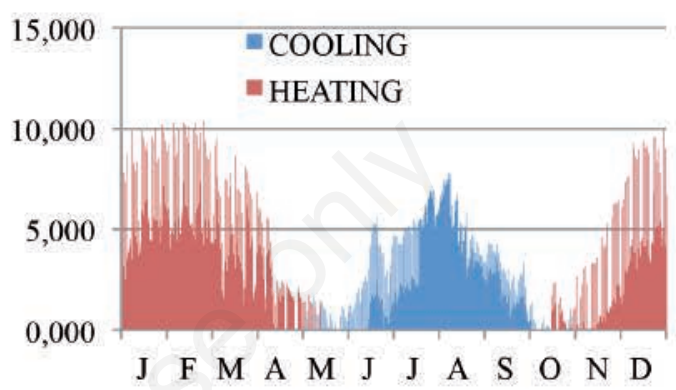

C) Heating and AC ( $\mathrm{x}$ - time [h]; y - energy [kWh])

D) Heating and AC ( $\mathrm{x}$ - time [h]; y - energy [kWh])
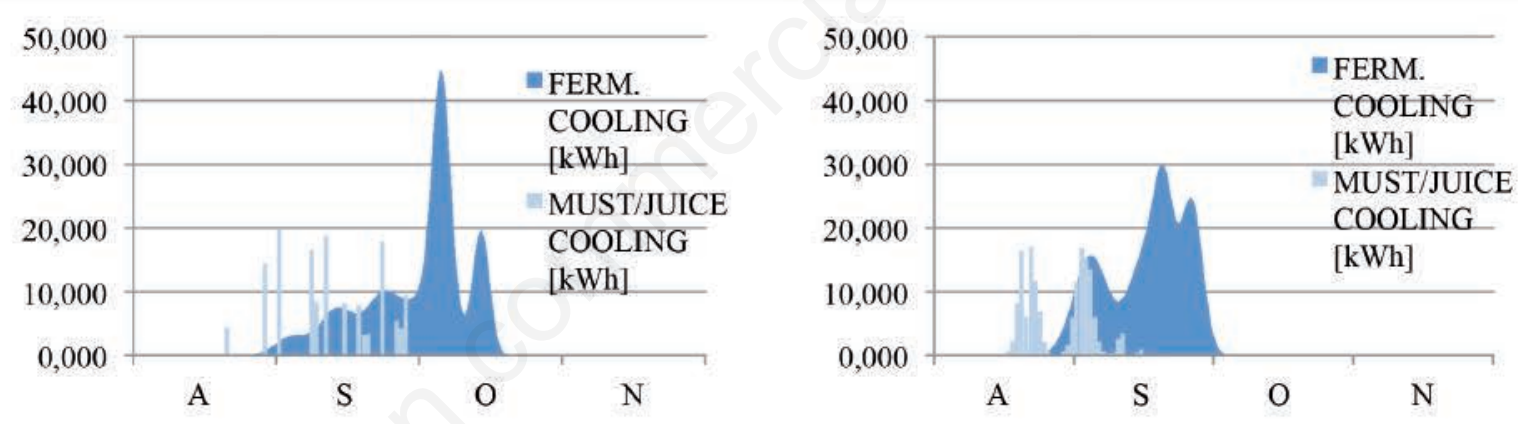

E) Cooling ( $\mathrm{x}$ - time $[\mathrm{h}] ; \mathrm{y}$ - energy [kWh])

F) Cooling ( $\mathrm{x}$ - time $[\mathrm{h}]$; y - energy [kWh])
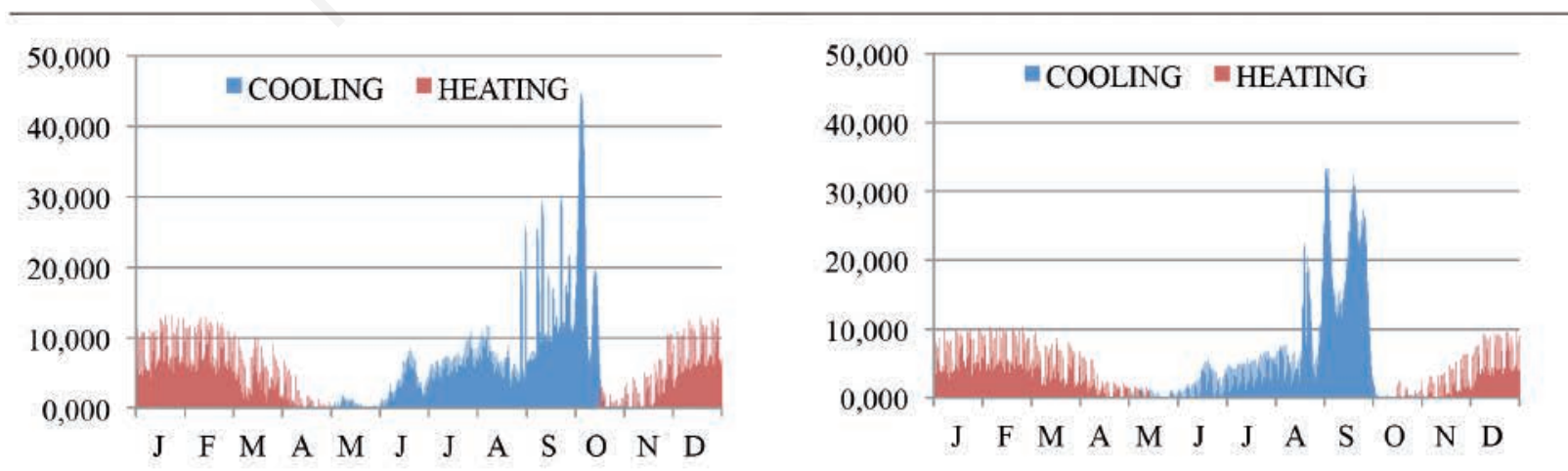

G) Total loads ( $\mathrm{x}$ - time [h]; y - energy [kWh])

H) Total loads ( $\mathrm{x}$ - time $[\mathrm{h}]$; $\mathrm{y}$ - energy [kWh])

Figure 8. Winery energy demand for thermal loads. Positive loads (heating) are highlighted in red, negative (cooling) in blue. 
involved in the project to take the final design solution. Considering the high costs of excavation and underground wall construction, insulation can represent a valid alternative if applied to all rooms. Underground solutions on the contrary can be preferred when excavation is anyhow necessary (for example, if deep foundations are necessary), or in case of specific municipal or landscape protection constraints (i.e., aboveground volume thresholds, landscape integration requirements, etc.).

\section{References}

Agenzia Regionale Protezione Ambiente. 2017. ARPAE Idro Meteo Clima. Available from: https://www.arpae.it/sim/?previsioni/regionali

Ayuga F. 1999. Wine processing. In: CIGR Handbook of Agricultural Engineering. St. Joseph, MI, USA, pp. 419-446.

Barbaresi A., Dallacasa F., Torreggiani D., Tassinari P. 2017. Retrofit interventions in non-conditioned rooms: calibration of an assessment method on a farm winery. J. Build. Perform. Simulat. 10:91-104.

Barbaresi A., De Maria F., Torreggiani D., Benni D., Tassinari P. 2015. Performance assessment of thermal simulation approaches of wine storage buildings based on experimental calibration. Energy Build. 103:307-16.

Barbaresi A., Torreggiani D., Benni D., Tassinari P. 2014. Underground cellar thermal simulation: definition of a method for modelling performance assessment based on experimental calibration. Energy Build. 76:363-72.

Boulton R. 1980. The prediction of fermentation behavior by a kinetic model. Am. J. Enol. Viticult. 31:1.

Boulton R.B., Singleton, V.L., Bisson, L.F., Kunkee, R.E. 1998. Principles and practices of winemaking. Springer, New York, NY, USA.

Casamonti M., Pavan V. 2004. Cantine architetture 1990-2005. Motta Editore, Milano, Italy.

Coleman M.C., Fish R., Block D.E. 2007. Temperature-dependent kinetic model for nitrogen-limited wine fermentations. Appl. Environ. Microbiol. 73:5875-84.

De Rosis A., Barbaresi A., Torreggiani D., Benni D., Tassinari P. 2014. Numerical simulations of the airflows in a wine-aging room: a lattice Boltzmann-immersed boundary study. Comput. Electron. Agricult. 109:261-70.

Failla A., Tomaselli G., Strano L. 2008. The definition of planning criteria for safe workplaces in wineries. In: Innovation Technology to Empower Safety, Health and Welfare in Agriculture and Agro-food Systems, Ragusa, Italy.

Fichera C.R., Tomaselli G., Di Fazio S. 1995. La metaprogettazione edilizia per l'industria agraria. Note di metodo. Riv. Ing. Agr. 18:45-58.

Italian Regulation. 2006. Decreto Legislativo 29 dicembre 2006, n. 311 - Disposizioni correttive ed integrative al decreto legislativo 19 agosto 2005, n. 192, recante attuazione della direttiva 2002/91/CE, relativa al rendimento energetico nell'edilizia. In: G.U. Ser. Gen. n. 26, 01/02/2007 - Suppl. Ord. n. 26.

Jacquet P., Capdeville C. 2007. Installazioni vinicole. Eno-One,
Reggio Emilia, Italy.

Marescalchi C. 1965. Manuale dell enologo (Winemaking Manual). Fratelli Marescalchi, Casale Monferrato, Italy.

Martin S., Canas I. 2006. A comparison between underground wine cellars and aboveground storage for the aging of Spanish wines. Trans. ASABE 49:1471-8.

Mazarrón F., Cañas Guerrero I. 2008. Exponential sinusoidal model for predicting temperature inside underground wine cellars from a Spanish region. Energy Build. 40:1931-40.

Mazarrón F., Cid-Falceto J., Cañas Guerrero I. 2012. An assessment of using ground thermal inertia as passive thermal technique in the wine industry around the world. Appl. Therm. Engine. 33/34:54-61.

Notarnicola B., Tassielli G., Nicoletti G.M. 2003. LCA of wine production. In: B. Mattsonn, U. Sonesson (Eds.), Environmentally-friendly food processing. WoodheadPublishing and CRC Press, Cambridge-England, Boca Raton, USA, XVII:306-326.

Ough C.S. 1966. Fermentation rates of grape juice. II effect of initial ${ }^{\circ}$ Brix, $\mathrm{pH}$, and fermentation temperature. Am. J. Enol. Viticult. 17:1.

Porras-Amores C., Mazarrón F., Cañas Guerrero I. 2014. Study of the vertical distribution of air temperature in warehouses. Energies 7:1193-206.

Reynolds A., Cliff M., Girard B., Kopp T.G. 2001. Influence of fermentation temperature on composition and sensory properties of Semillon and Shiraz Wines. Am. J. Enol. Viticult. 52:23540.

Rugani B., Vazquez-Roew I., Benedetto G., Benetto E. 2013. A comprehensive review of carbon footprint analysis as an extended environmental indicator in the wine sector. J. Cleaner Prod. 54:61-77.

Tassinari P., Galassi S., Benni S., Torreggiani D. 2009. Il sistema costruito delle aziende vitivinicole: una metodologia di analisi del comparto per la definizione dei requisiti metaprogettuali. In: IX Convegno Nazionale dell'Associazione Italiana di Ingegneria Agraria, pp. 12-16.

Tassinari P., Torreggiani D., Benni S., Dall'Ara E. 2013. Landscape quality in farmyard design: an approach for Italian Wine farms. Landscape Res. 38:729-49.

Tinti F., Barbaresi A., Benni S., Torreggiani D., Bruno R., Tassinari P. 2014. Experimental analysis of shallow underground temperature for the assessment of energy efficiency potential of underground wine cellars. Energy Build. 80:451-60.

Tinti F, Barbaresi A., Benni S., Torreggiani D., Bruno R., Tassinari P. 2015. Experimental analysis of thermal interaction between wine cellar and underground. Energy Build. 104:275-86.

Torreggiani D., Benni S., Garcia A.I., Ayuga F., Tassinari P. 2014. Farm winery layout design: size analysis of base spatial units in an Italian study area. Trans. ASABE 57:625-33.

Ventura F. Facini O., Gorgiadis T., Nardino M., Rossi F. 2007. Indagine sui flussi di materia ed energia da vigneto e daterreno nudo nell'interfilare in un sistema viticolo dell'Italia Centrale. Quad. Viticolt. Enol. 27-41.

Zamora F. 2003. Elaboracion y crianza del vino tinto: aspectos cientificos y praticos. Mundi-Pren., Madrid, Spain. 